\title{
Analysis of ice plains of the Filchner-Ronne Ice Shelf, Antarctica, using ICESat laser altimetry
}

\author{
Kelly M. BRUNT, ${ }^{1,2}$ Helen A. FRICKER, ${ }^{2}$ Laurie PADMAN ${ }^{3}$ \\ ${ }^{1}$ NASA Goddard Space Flight Center/GESTAR, 8800 Greenbelt Road, Greenbelt, Maryland 20771-9997, USA \\ E-mail: kelly.m.brunt@nasa.gov \\ ${ }^{2}$ Institute of Geophysics and Planetary Physics, Scripps Institution of Oceanography, University of California, San Diego, \\ 9500 Gilman Drive, La Jolla, California 92093-0225, USA \\ ${ }^{3}$ Earth \& Space Research, 3350 SW Cascade Ave., Corvallis, Oregon 97333-1536, USA
}

\begin{abstract}
We use repeat-track laser altimeter data from the Ice, Cloud and land Elevation Satellite (ICESat) to map the grounding zone (GZ) of the Filchner-Ronne Ice Shelf, Antarctica. Ice flexure in the GZ occurs as the ice shelf responds to ocean-height changes due primarily to tides. We have identified three 'ice plains', regions of low surface slope near the GZ where the ice is close to hydrostatic equilibrium: one on Institute Ice Stream; another to its east; and another west of Foundation Ice Stream. The vertical information from repeated ICESat tracks enables us to study the topography, state of flotation and flexure characteristics across these features. In regions of ephemeral grounding, tidal migration of the grounding line allows us to estimate bed slope $\left(\sim 1-2 \times 10^{-3}\right)$. From these studies we develop a classification scheme for ice plains, expressed in terms of the evolution, or 'life cycle', of these features. A lightly grounded ice plain progresses to a state of ephemeral grounding as the ice sheet thins near the GZ. Once sufficient thinning has occurred, the ice plain becomes a fully floating, relict ice plain with an undulated surface topography similar to that of lightly grounded ice; we expect viscous relaxation to a smooth ice-shelf surface to occur over a timescale of decades. Our improved insight into ice-plain evolution suggests added complexity in modeling ice in the vicinity of the GZ, and a role for ice-plain observations as a guide to relatively rapid changes in icesheet mass balance.
\end{abstract}

\section{INTRODUCTION}

Predicting the evolution of the Antarctic ice sheet is critical to determining its future contribution to global sea level. This task requires accurate representation of the ice sheet in coupled Earth system models, which in turn requires knowledge of ice-sheet processes and boundary conditions. One important boundary is the grounding line $(\mathrm{GL})$, which delineates grounded ice from floating ice. The GL lies within a broad (several $\mathrm{km}$ ) transitional band called the grounding zone (GZ), which extends from a landward limit, where the influence of the marine margin does not undergo vertical motion, to a seaward limit, where the ice floats hydrostatically on the ocean (Fig. 1). The processes influencing the force balance and resulting mass flux across the GZ are complex. Furthermore, the transition from a limited-slip to free-slip basal boundary condition is abrupt, and is controlled by bedrock and till characteristics, ice thickness, ocean height variability and basal melt rates modulated by changes in ocean temperature and circulation.

With the advent of numerical models capable of coupling the grounded ice sheet with the floating ice shelves, including potential GL migration (e.g. Joughin and others, 2010), we require improved knowledge of the location and structure of the GZ for initializing and validating these models. For specific settings, the GL can migrate rapidly in response to changes in ice dynamics, ice thickness and sea level (Schoof, 2007). Repeat mapping using interferometric synthetic aperture radar (InSAR) can provide some of this information; for example, Rignot (1998) used InSAR to document rapid retreat of the Pine Island Glacier GL associated with glacier thinning.
Analyses of repeat-track laser altimeter profiles from the Ice, Cloud and land Elevation Satellite (ICESat) (Fricker and Padman, 2006; Fricker and others, 2009; Brunt and others, 2010) provide an alternative view of the structure and variability of the GZ that is complementary to InSAR analyses. Specific features of a typical GZ are shown in Figure 1a. Point $G$, the true grounding line or point where ice first loses contact with the till/bedrock, can be located with either surface-based (Smith, 1991; Vaughan, 1994; Anandakrishnan and others, 2007; Lambrecht and others, 2007; Catania and others, 2010) or airborne (Crabtree and Doake, 1982) radar surveys. However, point $G$ is usually close to point $F$, the landward limit of flexure associated with tide-induced vertical movement of the ice shelf. Point $\mathrm{H}$ is the 'hydrostatic point', where the ice first reaches approximate hydrostatic equilibrium. Points $\mathrm{F}$ and $\mathrm{H}$, which bound the region of the ice shelf that undergoes short-term, tidalinduced flexure, can be located using satellite-based techniques, including differential InSAR (Gray and others, 2002; Fricker and others, 2009) and ICESat repeat-track analysis (Fricker and Padman, 2006; Fricker and others, 2009; Brunt and others, 2010). Point $I_{m}$ is the topographic minimum associated with a nonhydrostatic ice flexure response just seaward of point $F$. Point $I_{b}$ is the local break-in-slope as the ice tends toward that minimum. Both points $I_{m}$ and $I_{b}$ can be located using ICESat repeat-track analysis; additionally, point $\mathrm{I}_{\mathrm{b}}$ can be located through the analysis of surface shading in Moderate Resolution Imaging Spectroradiometer (MODIS) Mosaic of Antarctica (MOA) imagery (Scambos and others, 2007; J. Bohlander and T. Scambos, http:// nsidc.org/data/atlas/news/antarctic_coastlines.html. 

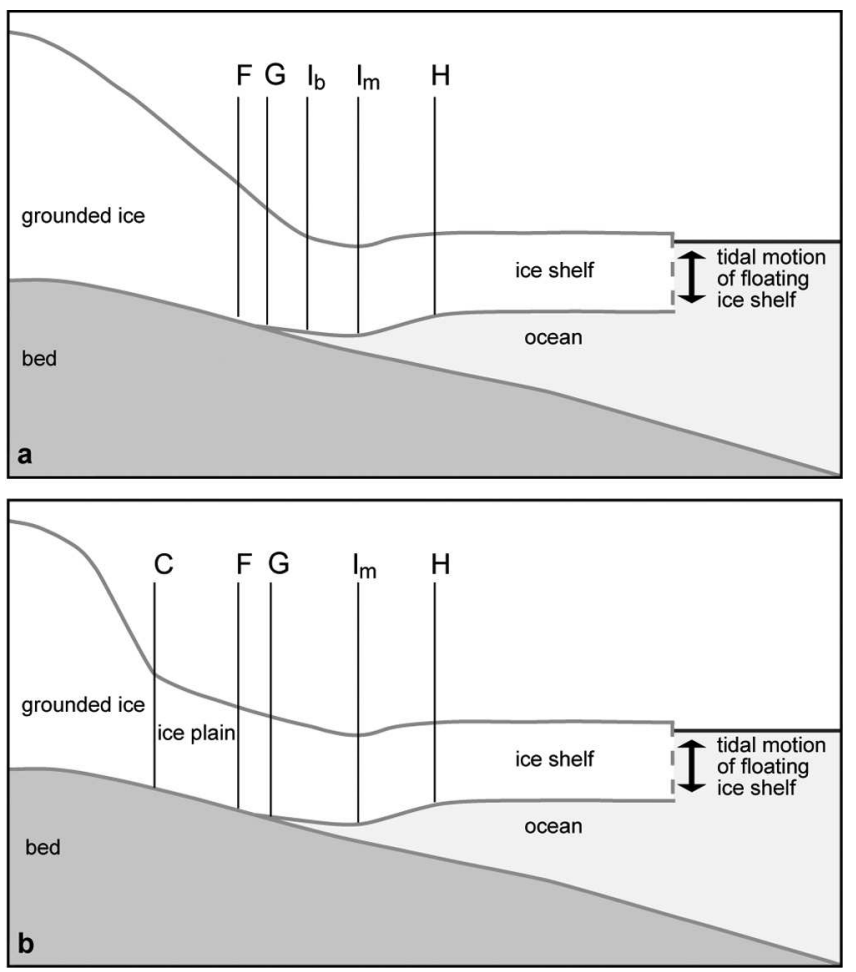

Fig. 1. Schematic cross-section diagrams showing the key features of an ice-shelf GZ, based on Corr and others (2001) and Fricker and others (2009) for (a) a typical GZ with no ice plain and (b) a GZ when an ice plain is present. (a) Point $F$ is the landward limit of ice flexure from tidal movement; point $G$ is the true GL where the grounded ice first loses contact with the bed; point $I_{b}$ is the breakin-slope; point $I_{m}$ is the local minimum in topography; and point $\mathrm{H}$ is the hydrostatic point where the ice first reaches approximate hydrostatic equilibrium. (b) When ice plain is present, point $C$ is the coupling line, or the upstream limit of the ice plain and the first break-in-slope.

In previous studies we have used multiple satellite datasets to map the GZ of the Amery Ice Shelf (Fricker and others, 2009) and Ross Ice Shelf (Brunt and others, 2010). In both studies we found small regions where point $\mathrm{I}_{\mathrm{b}}$ was many kilometers landward of point F. We interpreted these regions as ice plains, defined as grounded ice adjacent to the GL with low surface slope (Alley and others, 1989). In some regions, there can be multiple breaks-in-slope near the GZ (e.g. on the southern Amery Ice Shelf; see Fricker and others, 2009, fig. 6). In these cases, we place $I_{b}$ as the point where the grounded ice stream, flowing toward the GZ, first demonstrates a significant change in slope. The first breakin-slope for the GZ in the presence of an ice plain can be well upstream of point $\mathrm{I}_{\mathrm{b}}$ and is referred to as the 'coupling line' (Corr and others, 2001), or point C (Fig. 1b). Within ice plains, small changes in variables such as sea level or ice thickness can lead to large changes in the basal shear stress experienced by the overriding ice; therefore, monitoring ice plains may provide early indications of significant changes in ice-sheet behavior.

In this paper, we report on mapping the GZ features of the Filchner-Ronne Ice Shelf (FRIS). We have two goals: (1) to develop an improved GZ location dataset for use in ice-sheet models and as a benchmark for detecting ice-shelf change; and (2) to develop a better understanding of the structure of ice plains. The GZ of the FRIS has previously been mapped using combinations of ground-based (Lambrecht and others,
2007) and satellite techniques (Lambrecht and others, 2007; Scambos and others, 2007; J. Bohlander and T. Scambos, http://nsidc.org/data/atlas/news/antarctic_coastlines.html). Our primary contribution to improved mapping is the use of ICESat repeat-track altimeter profiles following the method described in previous studies of the Amery and Ross ice shelves (Fricker and others, 2009; Brunt and others, 2010). Fricker and Padman (2006) previously reported results for a few ICESat repeat-track profiles across the southwestern portion of the FRIS GZ near Institute Ice Stream, but only as a demonstration of ICESat's potential for GZ detection, not as a mapping effort.

Ice plains have previously been identified in the southern part of the FRIS, near the mouths of Institute (Jankowski and Drewry, 1981; Scambos and others, 2004; Fricker and Padman, 2006) and Foundation (Lambrecht and others, 2007) ice streams. We extend these studies by taking advantage of ICESat's ability to simultaneously map surface elevation and tide-induced flexure, allowing for better characterization of ice-plain structure. This study leads to a classification scheme for ice plains based on their surface topography and flotation state, which can be applied to other regions of Antarctica and suggests an ice-plain 'life cycle' that may provide information on long-term evolution of the ice sheet near the marine margin.

\section{METHODS}

\section{ICESat data and processing}

The Geoscience Laser Altimeter System (GLAS) on board ICESat (Schutz and others, 2005) sampled 50-70 m diameter footprints every $\sim 172 \mathrm{~m}$ along each track, with elevation retrieval precision and accuracy of $\sim 2$ and $\sim 14 \mathrm{~cm}$, respectively (Shuman and others, 2006). ICESat's southern limit of $86^{\circ} \mathrm{S}$ meant that it sampled all of Antarctica's floating ice shelves. Between October 2003 and October 2009 when data acquisition ceased, ICESat operated in 'campaign' mode two or three times per year (Schutz and others, 2005) with discrete 33 day data acquisition periods capturing the same 33 day sub-repeat cycle of a 91 day exact repeat cycle.

Our approach to estimating the GZ using ICESat repeattrack altimetry closely follows the technique described by Fricker and Padman (2006) and used by Fricker and others (2009) and Brunt and others (2010) for mapping the GZs of the Amery and Ross ice shelves, respectively. Specifically, we used GLA12, Release 428 data for the 17 ICESat campaigns between October 2003 and October 2009. We converted the ICESat locations and elevations from the TOPEX/Poseidon ellipsoid to the World Geodetic System 1984 (WGS84) ellipsoid (for consistency with other polar altimetry datasets) and applied the saturation corrections provided in GLA12. Finally, we applied our 'rejection criteria', which included the removal of tracks based on cloud cover and large cross-track offset. Specifically, we removed cloud-affected tracks, based on high gain values and low return energy levels. We then removed repeated passes with large cross-track offsets (greater than $\sim 100 \mathrm{~m}$ ) and interpolated along-track data to a nominal reference track whose location was the average of all the repeated passes (Brunt and others, 2010).

The uncertainties associated with cross-track error depend on the amount of track offset and the surface slope. 

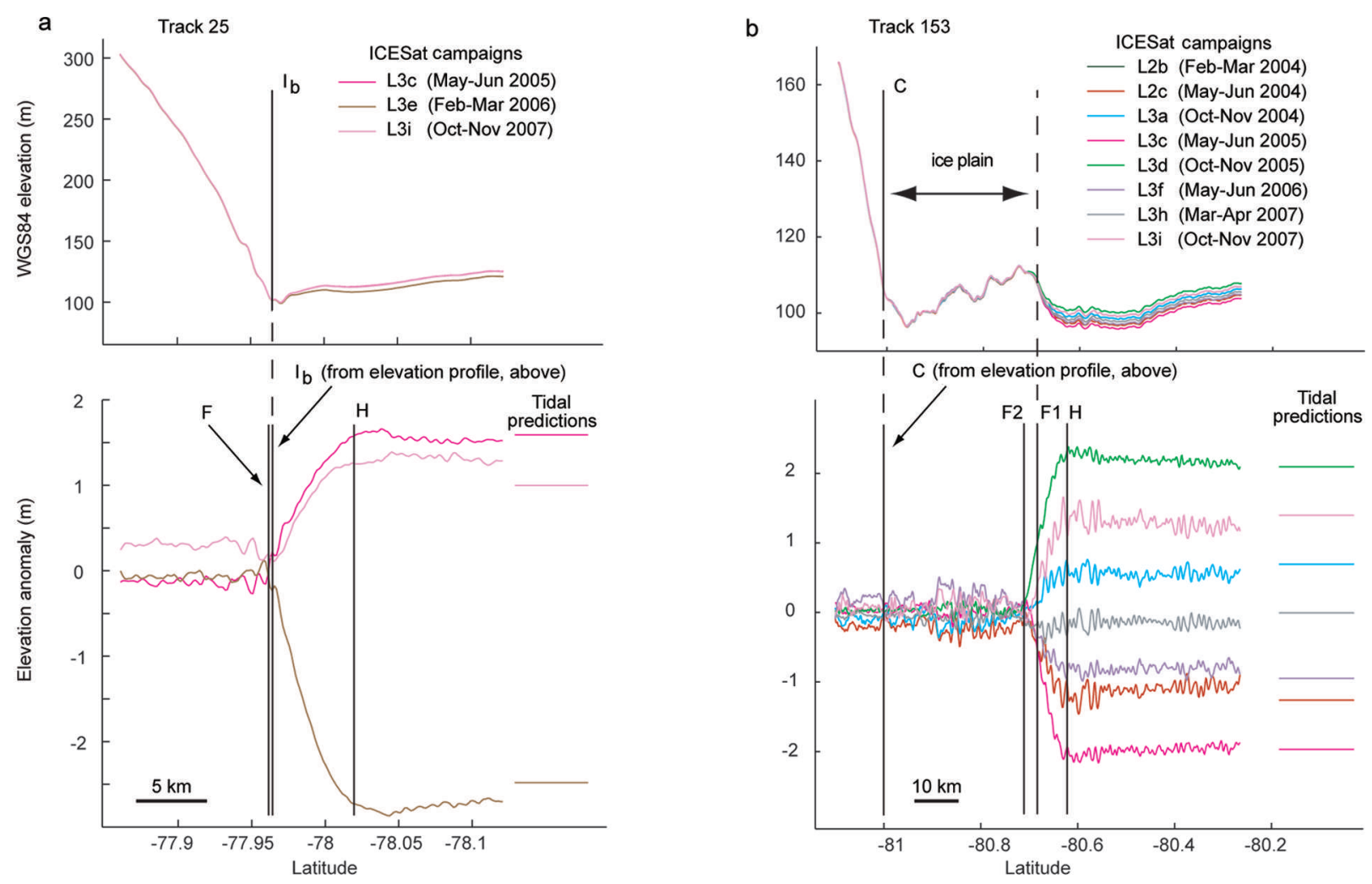

Fig. 2. Example of the estimation of $G Z$ parameters (points $I_{b}, F, H$ and $C$ ) from ICESat repeat-track analysis applied to two tracks that cross the FRIS GZ approximately normal to the MOA GL (see Fig. 3 for track locations). (a) Track 25, near Carlson Inlet. Top: set of 're-tided' ICESat surface elevation profiles relative to WGS84 ellipsoid for all valid repeated passes of track 25. Bottom: set of elevation anomalies, calculated by subtracting the reference elevation profile (i.e. the mean of all elevation profiles) from the individual elevation profiles. At the right are the tide height predictions from the CATS 2008a tide model (also referenced to zero mean; Padman and others, 2002) that correspond to each repeated pass. (b) Track 153, across a known ice plain near Institute Ice Stream. Top: similar to (a) but, in the presence of an ice plain, the first break-in-slope is the coupling point, C. Bottom: as in (a); however, point F migrates several kilometers with the tide, through the range delimited by F1 and F2.

While more sophisticated techniques have been developed to correct for these errors (e.g. Smith and others, 2009; Gardner and others, 2011; Zwally and others, 2011), we do not use those methods here since the assumption of timeindependent cross-track slope is not valid in the GZ and since they are more suited to the low-surface-slope regions of the ice-sheet interior, where the slopes are more uniform along repeat-track segments.

The GLA12, release 428, elevations have had predicted ocean and load tides removed using the GOT99.2 global ocean-tide model; however, identification of GZ features using repeat-track analysis is dependent on detecting the ice-shelf tidal response. Therefore, we 're-tided' these elevations, i.e. removed the applied tidal correction from the GLA12 elevations (Fricker and Padman, 2006). Maximum tidal range is typically $1-2 \mathrm{~m}$ for Antarctica but is up to $\sim 8 \mathrm{~m}$ in the southwestern corner of the FRIS (Padman and others, 2002).

\section{Estimation of grounding zone points}

We performed ICESat repeat-track analysis on a track-bytrack basis, following the method described by Brunt and others (2010). We first approximately located the FRIS GL visually, using the GL from MOA (J. Bohlander and T. Scambos, http://nsidc.org/data/atlas/news/antarctic_ coastlines.html) overlaid on MODIS MOA imagery (Scambos and others, 2007). For each track, we extracted the segment of the track that straddled the GL and then applied our rejection criteria. We interpolated the remaining repeated passes to a center-line reference track, using an along-track interpolation interval of $200 \mathrm{~m}$. We determined a mean along-track elevation profile, $h_{i}(x)$, and defined the 'elevation anomaly', $h_{i}^{\prime}(x, t)$, for each repeated pass as the difference of each elevation profile from $h_{i}(x)$; this is the same as referencing the profiles to a zero mean. This procedure resulted in a set of elevation anomaly profiles for each track.

The method of estimating the GZ points for each ICESat track is illustrated in Figure 2. For each track, we located point $I_{b}$ (the break-in-slope) by examining the shape of the surface topography in the set of ICESat elevation profiles (Fig. 2a, top panel); it is usually within $\sim 2 \mathrm{~km}$ of the MOA GL estimate. For this study, we are mapping more features of the GZ than MOA is capable of; however, with respect to our focus on ice plains, we are also interested in the regions where the separation of MOA and ICESat GL points is $>2 \mathrm{~km}$.

We estimated points $\mathrm{F}$ and $\mathrm{H}$ from analysis of the set of elevation anomaly profiles (Fig. 2a, bottom panel). For each track, we used the latitude and longitude associated with point $I_{b}$, and the times of each repeated pass, to predict the tidal heights using the Circum-Antarctic Tidal Simulation version 2008a ('CATS 2008a'), an update to the inverse model reported by Padman and others (2002). Predictions were made for the nearest water point in the CATS2008a $4 \mathrm{~km}$ grid. Tidal height predictions facilitate the estimation of points $\mathrm{F}$ and $\mathrm{H}$ in the elevation anomaly profiles by distinguishing tidal signal from other sources of elevation 


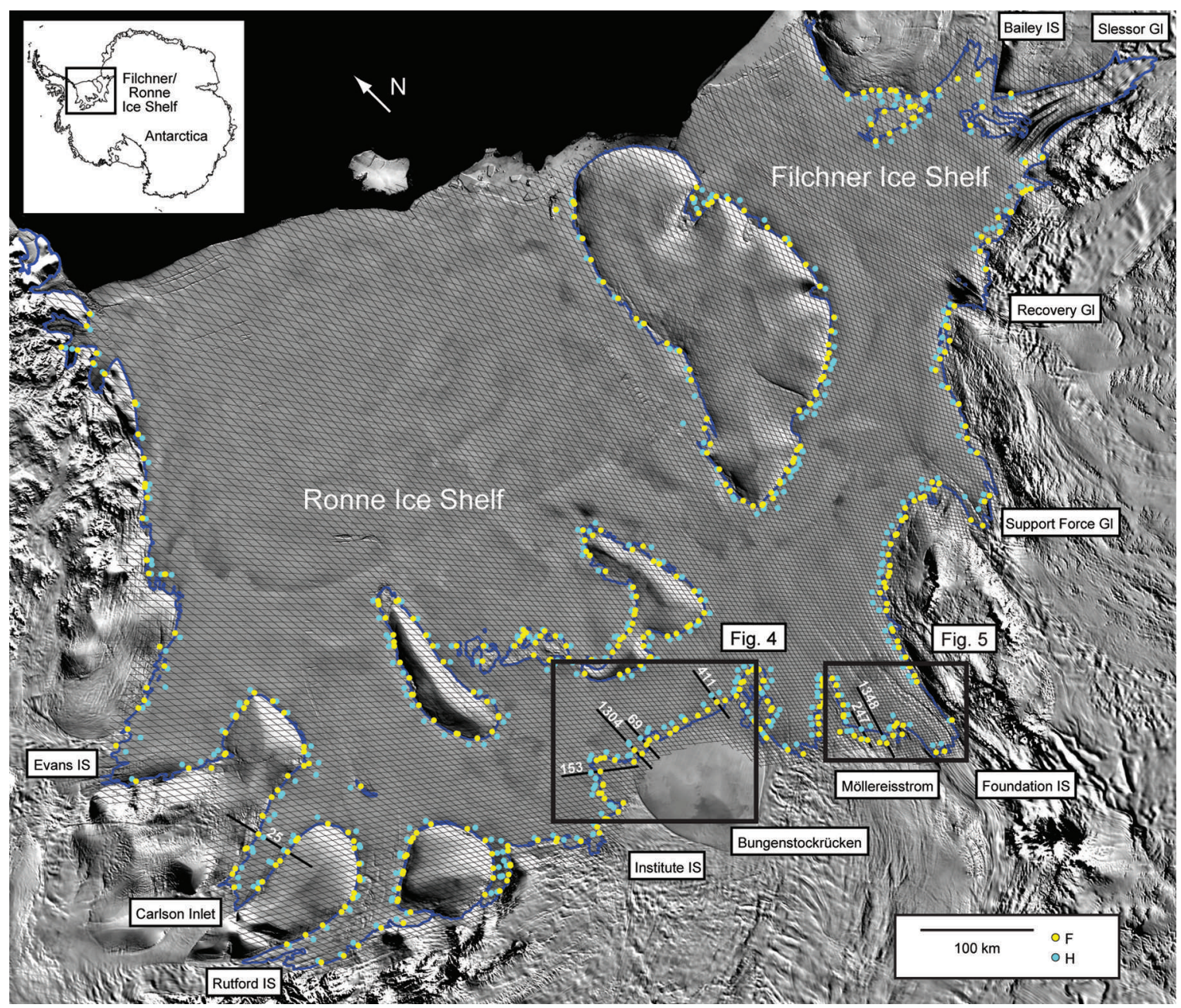

Fig. 3. Estimated locations of ICESat-derived GZ surface features (point F, yellow, and point $H$, cyan) around the perimeter of the FRIS including its islands and ice rises. Nominal ICESat ground tracks are shown as black lines. ICESat tracks used in Figures 2, 4 and 5 are thicker and numbered in white. Background MODIS MOA image and MOA GL (blue line) from US National Snow and Ice Data Center (NSIDC) (J. Bohlander and T. Scambos, http://nsidc.org/data/atlas/news/antarctic_coastlines.html; Scambos and others, 2007).

anomalies such as sampling of static topography by nonexact repeated tracks, accumulation or dynamic thinning (Brunt and others, 2010). We interpret the region where the elevation anomaly is close to zero (Fig. 2a, bottom panel, to the left of point F) as fully grounded ice, and the region where the elevation anomaly is close to the tidal predictions (Fig. 2a, bottom panel, to the right of point $\mathrm{H}$ ) as freely floating (hydrostatic) ice shelf.

If an ice plain is present, there is often more than one break-in-slope, making our interpretation of the ICESat repeat-track data slightly more complex. On ice plains, point $\mathrm{C}$, the coupling point described by Corr and others (2001), is generally the first break-in-slope in the vicinity of the GZ. Figure 2b, top panel, illustrates this for track 153, across an ice plain in the mouth of Institute Ice Stream. Ice plains also make the estimation of point $F$ more difficult, as the typically low bedrock slopes allow point $F$ to migrate longitudinally several kilometers with the tide; F1 in the bottom panel of Figure $2 b$ is an estimate of point $F$ from a set of repeated passes made at low tidal states, while F2 is an estimate made from repeated passes at high tidal states. The difference between the two estimates of point F (F1 and F2) in this example is $\sim 2 \mathrm{~km}$.

The two tracks used as examples in Figure 2 cross the FRIS GZ approximately normal to the MOA GL. For tracks that cross the GL obliquely, care is required when interpreting GZ structure and time dependence from relative along-track distances of specific features.

\section{RESULTS AND DISCUSSION}

\section{Mapping the FRIS grounding zone}

We estimated the location of 431 sets of GZ points $\left(I_{b}, F\right.$ and $\mathrm{H})$ for the FRIS, including its perimeter, islands and ice rises (Fig. 3). The FRIS GZ is included in a continent-scale, ICESat-derived GZ dataset (K.M. Brunt and others, http:// nsidc.org/data/nsidc-0469.html). These discrete GZ estimates have also been used in conjunction with Landsat-7 Enhanced Thematic Mapper Plus imagery to create a continuous, high-resolution Antarctic GL dataset, which describes the loci of points $\mathrm{H}$ and $\mathrm{I}_{\mathrm{b}}$ (Bindschadler and others, 2011; R. Bindschadler and others, http://www.nsidc. org/data/nsidc-0489.html).

Similar to the results of Brunt and others (2010) for the Ross Ice Shelf, most ICESat estimates of point $F$ are within $\sim 2 \mathrm{~km}$ of the MOA GL. Points $\mathrm{F}$ and $\mathrm{H}$ are usually easy to identify, in part due to the large tidal range in the southern Weddell Sea (Fricker and Padman, 2002; Padman and others, 2002). Since the ICESat tracks are not necessarily normal to 
the $\mathrm{GL}$, estimating the width of the flexural boundary between points $\mathrm{F}$ and $\mathrm{H}$ requires a conversion from alongtrack distance to cross-GL distance (to account for the crossing angle). We use the trend of the MOA GL as a guide to local GL orientation. After this rotation, the mean GZ width $(\mathrm{F}-\mathrm{H})$ is $\sim 5.2 \mathrm{~km}$ with a standard deviation of $2.7 \mathrm{~km}$. In one case, the GZ width exceeds $10 \mathrm{~km}$. We expect that GZ width depends on factors such as ice thickness and basal slope, but a study of these dependencies is beyond the scope of the present paper. (Bindschadler and others (2011, fig. 12) provide estimates of the relationship between ice thickness and the distance between points $\mathrm{I}_{\mathrm{b}}$ and $\mathrm{H}$.)

Mapping GZ features with ICESat repeat-track analysis becomes more challenging under certain circumstances: (1) large spacing between ICESat tracks (i.e. tracks are more coarsely spaced approaching the equator); (2) a small tidal range in the sampled set of campaigns; (3) high surface roughness; and (4) persistent cloud cover. The spacing of ICESat tracks on the FRIS is $\sim 5.5 \mathrm{~km}$ in the southeastern part of the ice shelf (near Foundation Ice Stream) but $\sim 19 \mathrm{~km}$ in the northwest part of the ice shelf (near the southern Antarctic Peninsula), where persistent cloud cover also degrades the GZ mapping. Full tidal range for the FRIS perimeter is generally large (>3 m; Padman and others, 2002). The FRIS surface is roughest in areas where the fast-flowing ice streams meet the ice shelf, especially near the outlets of Bailey Ice Stream and Slessor and Recovery glaciers on the eastern edge of the Filchner Ice Shelf. As a result, we obtained few reliable GZ location estimates in this area.

\section{Detection of ice plains}

Our analysis of ICESat altimetry confirmed the presence of three significant ice plains in the southern FRIS: (1) on Institute Ice Stream (Scambos and others, 2004); (2) to the east of Institute Ice Stream on the northern flank of Bungenstockrücken (Fricker and Padman, 2006); and (3) west of Foundation Ice Stream, downstream of Möllereisstrom (Lambrecht and others, 2007) (Fig. 3). We present mapping results for each of these regions, then compare them to develop a classification scheme for ice plains.

\section{Institute Ice Plain}

Institute Ice Plain is a diamond-shaped feature located near the mouth of Institute Ice Stream at its eastern margin (Fig. 4). This feature was first tentatively identified by Jankowski and Drewry (1981) from geophysical data, subsequently mapped as ice rumples by Heidrich and others (1992) and then mapped by Scambos and others (2004) based on satellite imagery. This ice plain was also studied by preliminary repeat-track analysis by Fricker and Padman (2006), using the first eight ICESat campaigns. The maximum along-ice-flow distance across the ice plain is $\sim 52 \mathrm{~km}$ (Scambos and others, 2004).

ICESat surface elevation profiles across this ice plain reveal the undulating nature of the ice surface between points $\mathrm{C}$ and $\mathrm{F}$ on ICESat track 153 (Fig. 2b, top panel); this track is aligned $\sim 55^{\circ}$ to the flow direction determined from streak lines visible in MOA. Seaward of point $F$ the ice surface is flatter and smoother, which is more typical of floating ice shelves. Within the ice plain there is no tide-induced elevation change observed in the ICESat elevation anomaly profiles (Fig. 2b, bottom panel), indicating that it is grounded.

Based on these characteristics, we suggest that Institute Ice Plain is similar to the ice plains observed on Pine Island
Glacier (Corr and others, 2001) and Whillans Ice Stream (Bindschadler and others, 2003; Winberry and others, 2009) on the Ross Ice Shelf.

\section{Bungenstockrücken}

The ice plain immediately to the east of Institute Ice Plain, north of Bungenstockrücken, was originally identified by Fricker and Padman (2006) based on repeat-track analysis of the first eight ICESat campaigns. These authors found that the first break-in-slope was $\sim 10 \mathrm{~km}$ upstream of point $\mathrm{F}$ and, by analogy with observations on Pine Island Glacier reported by Corr and others (2001), interpreted this region as an ice plain.

Based on our analysis of the complete set of repeated passes of the ICESat tracks across Bungenstockrücken, we now suggest that this narrow $(<10 \mathrm{~km}$ normal to the $\mathrm{GL})$ ice plain extends farther east than was proposed by Fricker and Padman (2006) and includes the entire GZ on the northern flank of Bungenstockrücken. Our suggestion is based on the difficulty of estimating the location of point $F$ in this region as this point migrates with the tide (Fig. 4), which indicates low bed slope. Using the descending ICESat tracks, which are generally approximately normal to the MOA GL, a typical location for point $\mathrm{F}$ can be estimated as the point where the majority of repeated passes begin to show flexure associated with tidal movement (yellow dots in Fig. 4a and labeled F1 in Fig. 4b). However, some of the tracks across the Bungenstockrücken GZ include a repeated pass acquired at higher tide that indicates a limit of flexure farther landward (orange dots in Fig. 4a and labeled F2 in Fig. 4b). This observation suggests that the region between F1 and F2 in Figure 4 is grounded at low tide and floating at high tide, a condition referred to as 'ephemeral grounding' by Schmeltz and others (2001). On any track, identifying the entire region of ephemeral grounding requires sampling the full tidal range. However, even a partial sampling of tide range can be used to identify apparent bed slope, which can be used to extrapolate the migration of point $\mathrm{F}$ over the full predicted tidal range. The width of the region between F1 and F2, typically a few kilometers normal to the $\mathrm{GL}$, increases as the tidal range increases (Fig. 4b). The tracks on the northern flank of Bungenstockrücken that do not have evidence of a migrating point $F$ are generally those for which no repeated passes were acquired at a time of high tide.

Variability in the position of point $\mathrm{F}$ due to tides at Bungenstockrücken led us to conclude that the MOA GL generally represents point $C$, as it is the first break-in-slope in the vicinity of the GZ (Fig. 4).

\section{Möllereisstrom}

The GL for the ice plain at the mouth of Möllereisstrom (Fig. 5), to the west of Foundation Ice Stream in the southern FRIS, was estimated by Lambrecht and others (2007) based on a combination of radar, seismic and hydrostatic inversion techniques. Downstream of Möllereisstrom, there is a consistent separation of $\sim 10 \mathrm{~km}$ between the MOA GL and the GL of Lambrecht and others (2007) (Fig. 5a). Lambrecht and others (2007) hypothesized that the region between their GL and the MOA GL in the mouth of Möllereisstrom is an ice plain, noting that this region was 'near flotation' in many places. Based on ICESat repeat-track analysis, the first break-in-slope (in this case, point C) is close to the Lambrecht and others (2007) GL. The MOA GL in this vicinity is coincident with ICESat point $\mathrm{H}$, where the 

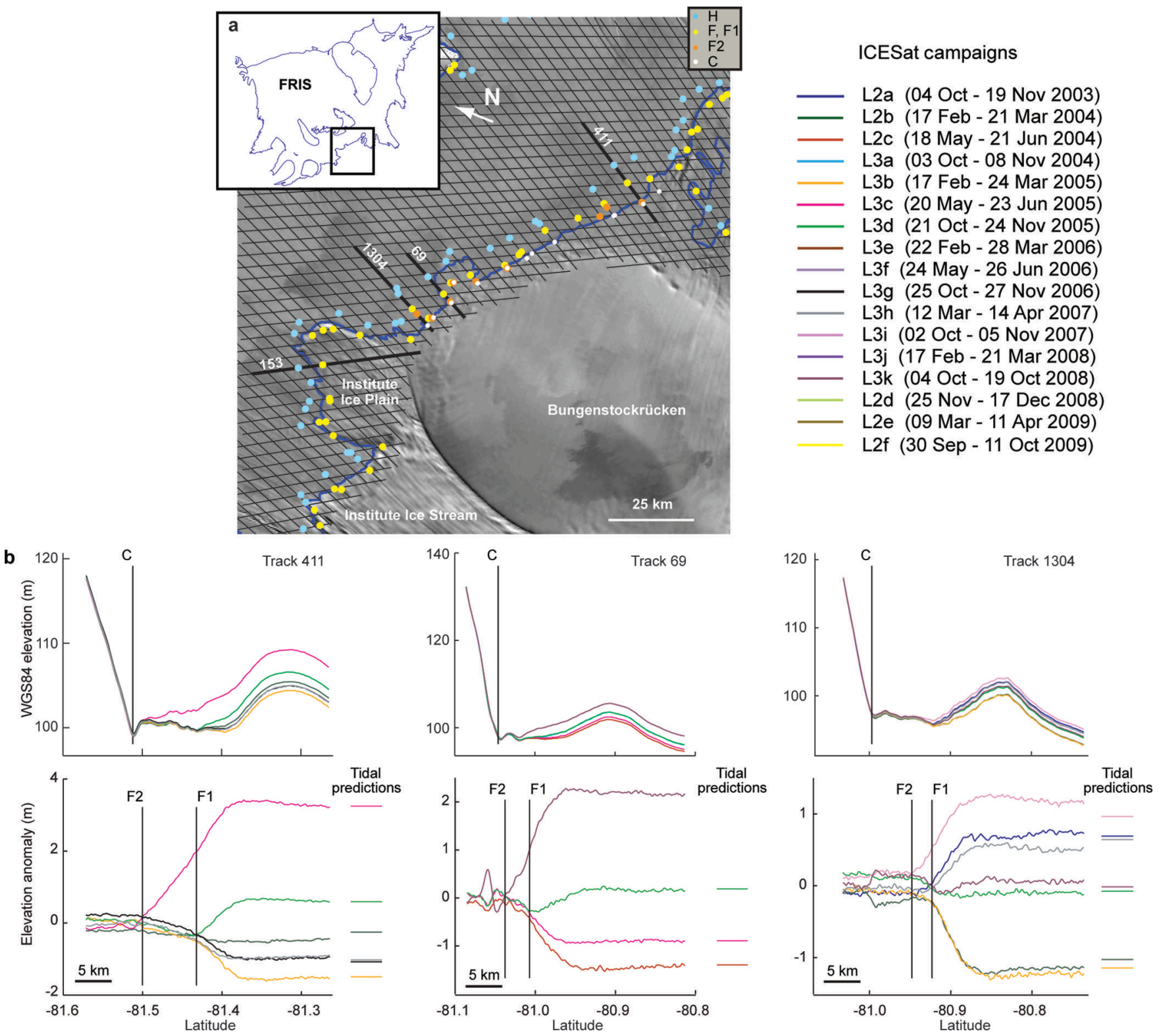

Fig. 4. (a) Location of ICESat tracks across the GL of Bungenstockrücken. Tracks whose profiles are shown in this and later figures are thicker and numbered in white. MOA image and the MOA GL (blue line) are from Scambos and others (2007) and J. Bohlander and T. Scambos (http://nsidc.org/data/atlas/news/antarctic_coastlines.html). Also shown are ICESat-derived points $\mathrm{F}$ and $\mathrm{H}$ (yellow and cyan points respectively), point $\mathrm{C}$ (white points, in the vicinity of ice plains), as well as the inland flexure limit (F2, orange points), which is seen in tracks that have sufficient tidal sampling. (b) 'Re-tided' ICESat surface elevation profiles and elevation anomalies for tracks 411, 69 and 1304 with corresponding (difference from mean) tide predictions at right. The range of point $\mathrm{F}$ is bound on the seaward side by the point where the majority of the repeated tracks begin to indicate flexure (F1), and on the landward side by the point where repeated passes acquired at high tide begin to indicate flexure (F2). Between F1 and F2 is a region of 'ephemeral grounding'; the distance between F1 and F2 varies with the maximum tide value and can be as large as $\sim 10 \mathrm{~km}$.

ice reaches approximate hydrostatic equilibrium (Fig. 5b). The elevation anomalies also reveal that much of the region identified as an ice plain by Lambrecht and others (2007) is currently floating (Fig. 5b). The signal near point $\mathrm{C}$ in the elevation anomalies (Fig. 5b) is the result of cross-track error associated with the fact that the ICESat tracks are oblique $\left(\sim 40^{\circ}\right)$ to the coupling line which represents a significant change in gradient. This example illustrates the value of looking at predicted tide heights while analyzing repeattrack altimetry near the GZ.

We found that migration of point $F$ seen in tracks across the Bungenstockrücken Ice Plain also occurred on Möllereisstrom. This migration made the estimation of point $\mathrm{F}$ difficult; a range in estimates of point $\mathrm{F}$ was sometimes observed (F1 and F2 in Fig. 5b) on tracks with one or more repeat passes acquired at higher tides. Within the ice plain we measured distances between F1 and F2 of up to $5 \mathrm{~km}$ normal to the GL.

Comparisons of our ICESat repeat-track observations with tidal predictions demonstrate that much of the region designated as Möllereisstrom Ice Plain by Lambrecht and others (2007) is permanently floating, and never grounds even at low tide (seaward of F1 in Fig. 5b). The surface topography is, however, more consistent with lightly grounded ice than with floating ice. We hypothesize that this portion of the ice sheet has only recently become fully 

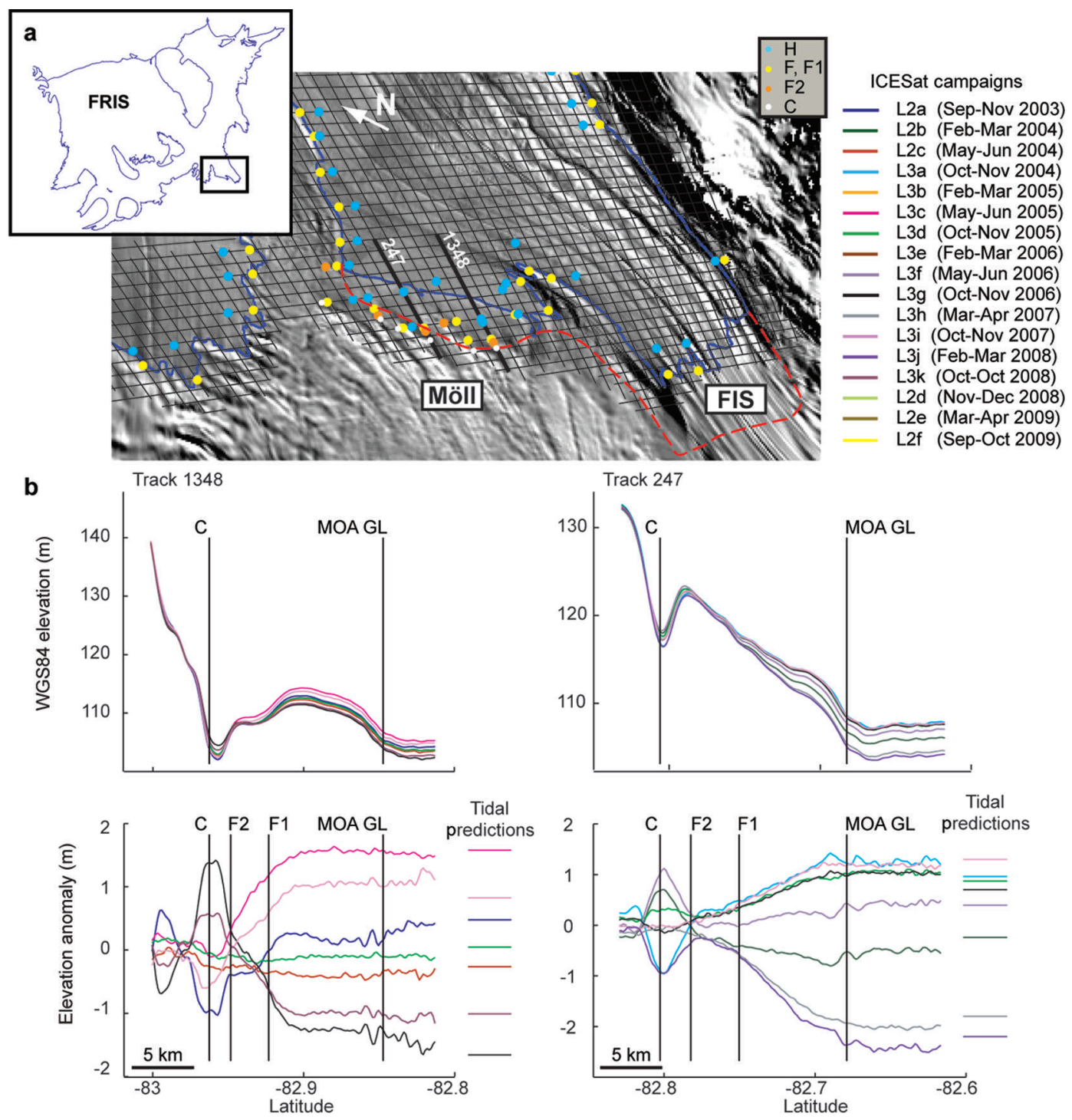

Fig. 5. (a) Location of ICESat tracks across the GL of Möllereisstrom (Möll) and Foundation Ice Stream (FIS). Tracks whose profiles are shown are thicker and numbered in white. MOA image and the MOA GL (blue line) are from J. Bohlander and T. Scambos (http://nsidc.org/data/ atlas/news/antarctic coastlines.html) and Scambos and others (2007); the GL of Lambrecht and others (2007) is the red dashed line. Also shown are ICESat-derived points $\mathrm{F}$ and $\mathrm{H}$ (yellow and cyan points respectively), point $\mathrm{C}$ (white points, in the vicinity of ice plains), as well as the inland flexure limit (F2, orange points). (b) 'Re-tided' ICESat surface elevation profiles and elevation anomalies for tracks 247 and 1348 , with corresponding tide predictions at right. Similar to Figure $4 \mathrm{~b}$, between F1 and F2 is a $<5 \mathrm{~km}$ region of 'ephemeral grounding'.

floating so that its thickness has not yet viscously adjusted to flotation, and refer to it as a 'relict ice plain'.

Much of the remaining ice plain experiences ephemeral grounding, similar to Bungenstockrücken Ice Plain. We suggest a redefinition of the areal extent for Möllereisstrom Ice Plain by including the region of ephemeral grounding, or the region where point $\mathrm{F}$ migrates with the tide (between $\mathrm{F} 1$ and F2 in Fig. 5b), and removing the permanently floating relict ice plain.

\section{Bedrock slope estimates}

Through analogy with better-surveyed ice plains on Pine Island Glacier and Whillans Ice Stream, we assume that the grounded ice downstream of the coupling point $\mathrm{C}$ is only lightly grounded. We have not estimated the hydrostatic anomalies along the ICESat tracks across the FRIS ice plains because gridded datasets do not exist at sufficiently small, $O(1) \mathrm{km}$, length scales across the GZ. Nevertheless, as Figures 2b, 4 and 5 illustrate, ice surface elevation can change by $O(10) \mathrm{m}$ over a single ice plain. If the ice remains grounded at all stages of the tidal cycle, we cannot estimate bed-slope magnitude or direction from the ICESat elevation data. For regions of ephemeral grounding, however, we know that the ice is approximately hydrostatically balanced throughout the region. Thus, to first order, the apparent bed slope in the direction of the ICESat track is given by

$$
\frac{\mathrm{d} h_{\mathrm{b}}}{\mathrm{d} x}=\frac{-\rho_{\mathrm{i}}}{\left(\rho_{\mathrm{o}}-\rho_{\mathrm{i}}\right)} \frac{\mathrm{d} h_{\mathrm{i}}}{\mathrm{d} x}
$$

where $\rho_{\mathrm{i}}$ and $\rho_{\mathrm{o}}$ are mean ice and ocean densities, respectively. Ignoring the surface low-density firn layer, and using $\rho_{\mathrm{i}}=917 \mathrm{~kg} \mathrm{~m}^{-3}$ and $\rho_{\mathrm{o}}=1028 \mathrm{~kg} \mathrm{~m}^{-3}, \mathrm{~d} h_{\mathrm{b}} / \mathrm{d} x$ $\approx-8.3 \mathrm{~d} h_{\mathrm{i}} / \mathrm{d} x$. This estimate of $\mathrm{d} h_{\mathrm{b}} / \mathrm{d} x$ should also be similar to $\Delta h_{\text {tide }} / \Delta x$, where $\Delta h_{\text {tide }}$ is the tidal range and $\Delta x$ is the along-track separation between the two estimates of point $F$ (F1 and F2).

For Institute Ice Plain (Fig. 2b), $\mathrm{d} h_{\mathrm{i}} / \mathrm{d} x \approx 2.5 \times 10^{-4}(0.5 \mathrm{~m}$ in $2 \mathrm{~km}$ ) in the region of ephemeral grounding between F1 
a
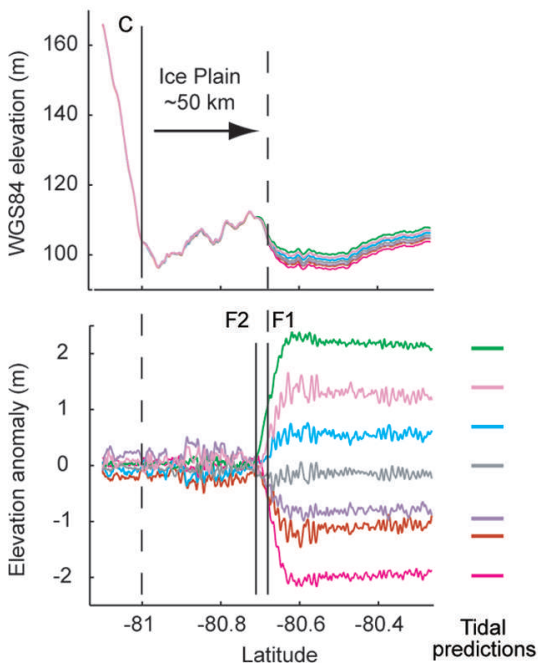

b

Track 411, Bungenstockrücken Ice Plain
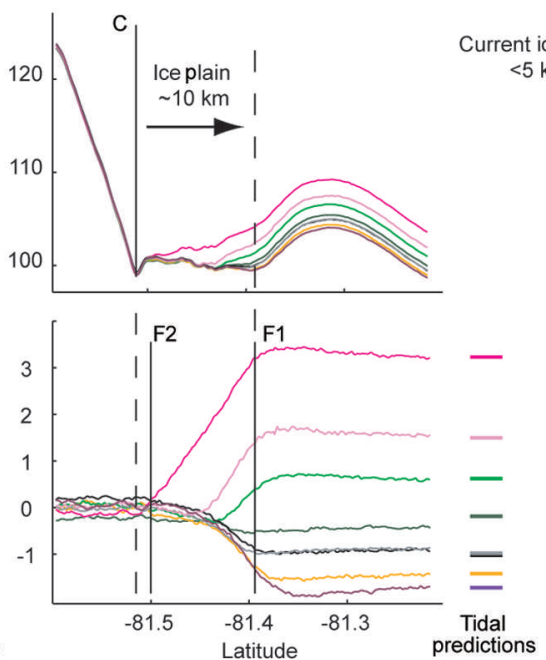

$c$
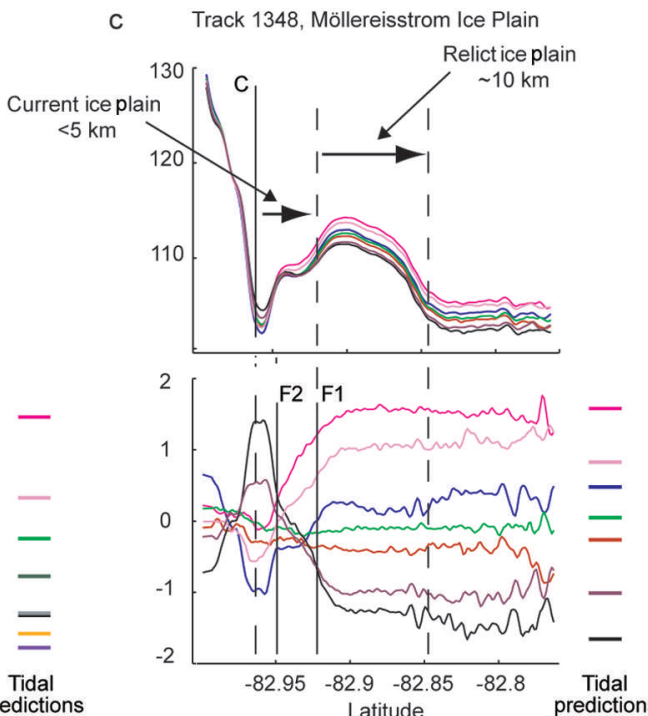

ICESat Campaigns L2a L2b L2c L3a L3b $3 \mathrm{c}$ $3 d$ $3 e$ -3f

Fig. 6. The classification, and inferred life cycle, of ice plains. ICESat surface elevation profiles (top) and elevation anomalies (bottom) for (from left to right) tracks 153 (Institute Ice Plain), 411 (Bungenstockrücken Ice Plain) and 1348 (Möllereisstrom Ice Plain). Estimations of points $\mathrm{C}$ and the limits of point $\mathrm{F}$ (denoted F1 and F2) are shown as vertical lines. See Figure 3 for location of tracks and Figure 4 for campaign dates. (a) An example of an ice plain that is 'lightly grounded' between points $\mathrm{C}$ and $\mathrm{F}$; (b) an example of an ice plain with evidence of 'ephemeral grounding' between F1 and F2; and (c) an example of a relict ice plain ('barely floating') with evidence of 'ephemeral grounding' between F1 and F2.

and $\mathrm{F} 2$, suggesting that $\mathrm{d} h_{\mathrm{b}} / \mathrm{d} x \approx 2 \times 10^{-3}$. Based on tidal range, $\mathrm{d} h_{\mathrm{b}} / \mathrm{d} x$ is $4 \mathrm{~m}(2 \mathrm{~km})^{-1}$, or also $2 \times 10^{-3}$. For Bungenstockrücken (Fig. 4), the surface slope between F1 and F2 is about $\left.1 \times 10^{-4}\left(1 \mathrm{~m}(10 \mathrm{~km})^{-1}\right)\right)$, so that $\mathrm{d} h_{\mathrm{b}} / \mathrm{d} x \approx 1 \times 10^{-3}$. Using tidal range, $\mathrm{d} h_{\mathrm{b}} / \mathrm{d} x$ is $6 \mathrm{~m}(7 \mathrm{~km})^{-1}$ (track 411 ) or $\sim 2.5 \mathrm{~m}(3 \mathrm{~km})^{-1}$ (track 69), both $\sim 1 \times 10^{-3}$. That is, for both ice plains, the calculations from both approaches give similar apparent bedrock slopes, of order $10^{-3}$, with a downward slope towards the ice shelf.

In both cases, within the region of ephemeral grounding, ice thins seaward. This is another indication that the bedrock slopes downward toward the ice shelf, and is consistent with the GL migrating across the seaward portion of the 'grounding zone wedge' structure described by Alley and others (2007). For Institute Ice Plain, (Fig. 2b), the permanently grounded ice between the coupling line and F2 thickens seaward, suggesting that the bedrock slopes upward toward the ice shelf. In contrast, the inferred bedrock slope for Bungenstockrücken Ice Plain is downward from the coupling line to F1. However, as noted previously, we cannot confirm these interpretations from the available bedrock elevation data.

\section{Ice-plain classification}

The three ice plains that we have identified on the FRIS have two common elements observed using ICESat repeat-track analysis: (1) they are regions of low surface slope (Fig. 6, top panels; downstream of point $\mathrm{C}$ on the surface elevation profiles), and thus the ice dynamics in these regions are subject to low gravitational driving stresses; and (2) the undulations of the local surface topography (Fig. 6, top panels) are more consistent with lightly grounded ice than with ice shelves, where the lack of a basal shear stress leads to low surface slope (Benn and Evans, 1998). Beyond these two common elements, the analysis of the FRIS GZ indicates that these ice plains represent three distinct classes, which a

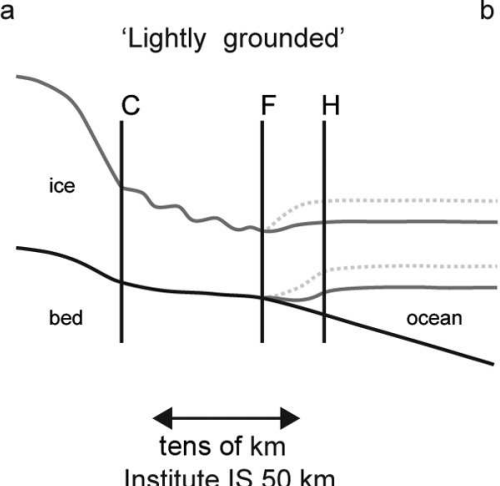

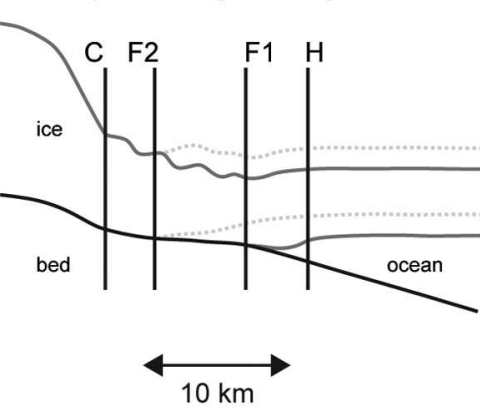

Bungenstockrücken 10 km

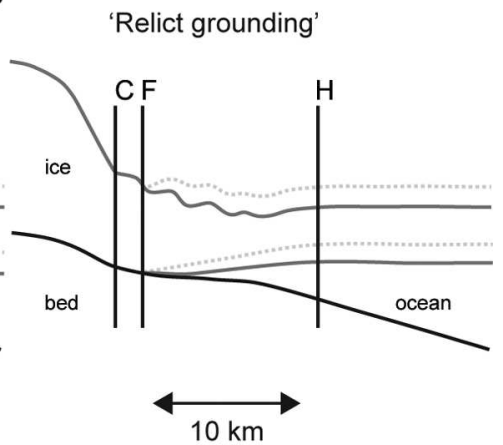

Möllereisstrom $10 \mathrm{~km}$

Fig. 7. The schematic life cycle of an ice plain at low and high (dashed line) tide, with examples from the FRIS. (a) A classic ice plain, where the region between points F and C is 'lightly grounded'; (b) a region of ephemeral grounding, where the flotation state between F1 and F2 is dependent upon the tidal state; and (c) a relict ice plain, where ice downstream of point $\mathrm{F}$ has recently become fully floating but the ice surface has not yet viscously conformed to flotation. 
are discussed below, illustrated by ICESat repeat-track profiles in Figure 6 and depicted schematically in Figure 7.

The classical definition of an ice plain (e.g. Alley and others, 1989; Bindschadler and others, 2003) includes the common elements 1 and 2 above, plus the qualification that the region must be 'lightly grounded'. This definition is appropriate for the Whillans Ice Plain and the ice plains on Institute Ice Stream and Pine Island Glacier.

Based on the analyses presented above, we propose a revised classification of ice plains that shares the common elements 1 and 2 mentioned above, but differs by extending the 'lightly grounded' criterion to include regions subject to ephemeral grounding, or whose degree of grounding varies over the tidal cycle. Specifically, this would include ice plains where the limit of tidal flexure migrates rapidly with the tide (e.g. the location of point $F$ for ICESat track 411 on Bungenstockrücken varies by almost $10 \mathrm{~km}$ with the semidiurnal tides of this region; Fig. 6b). Bungenstockrücken Ice Plain is narrow ( $10 \mathrm{~km}$ normal to the GL; Fig. 4$)$; the ephemerally grounded zone on Möllereisstrom (between F1 and F2 in Fig. 5) is up to $5 \mathrm{~km}$ wide, normal to the GZ; and there is evidence of $\mathrm{a} \sim 2 \mathrm{~km}$ migration of point $\mathrm{F}$ on Institute Ice Plain (Fig. 6a). While these length scales are small, $1-10 \mathrm{~km}$, the timescale at which point $\mathrm{F}$ migrates is short ( $\sim 6$ hours; half the dominant semidiurnal tidal period), illustrating the highly dynamic and sensitive nature of the $\mathrm{GZ}$ in regions of low bedrock slope.

An ice plain like Bungenstockrücken that experiences ephemeral grounding over a significant fraction of its area may constitute the transition between a 'lightly grounded' ice plain and ice that has become freely floating due to recent ice-sheet thinning, which leads to retreat in the position of the GL. Similar ephemeral grounding has been observed on Thwaites Glacier (Schmeltz and others, 2001), where InSAR analysis revealed that an ice rise transitioned from fully grounded to freely floating in $\sim 4$ years; this was attributed to rapid ice-shelf thinning. In addition, an ice rumple, observed in 1973 Landsat imagery of the ice shelf of Pine Island Glacier, had completely disappeared by 1982, as the ice shelf thinned dramatically in the intervening time (Jenkins and others, 2010).

The ice plain downstream of Möllereisstrom has the common elements 1 and 2, but is distinct from Institute and Bungenstockrücken ice plains because a significant area of the adjacent floating ice has undulating surface topography that is more typical of grounded ice. The surface undulations of the relict ice plain compared to the surface undulations on the part of the ice plain that is experiencing ephemeral grounding suggest that the relict ice plain of the Möllereisstrom GZ has only recently become fully floating and has not yet had time to viscously conform to the removal of basal shear stress and hydrostatic balance. This recent change in flotation state could be due to local ice-shelf thinning, which is suggested by radar altimeter surface elevation change results (Zwally and others, 2005).

We propose that the three types of ice plain described above represent three different stages of evolution experienced by an ice plain as the ice sheet near the GZ thins over time. With sufficiently thick ice, the ice plain is relatively well grounded so that short-timescale fluctuations in sea level (e.g. due to tides) have no significant impact on the grounded ice (Fig. 7a). As the ice thins, some portion of the ice plain becomes responsive to fluctuations in sea level; this region will become a band of ephemeral grounding provided that the basal slope is sufficiently small to support significant migration of the GL (Fig. 7b). The contribution of this band to the overall dynamics of the ice-sheet system presumably depends on the basal shear stress and the portion of the ice plain that is uplifted over the course of the tidal cycle.

With sufficient thinning, a portion of the ice plain will lift permanently off the bedrock/till to become part of the adjacent ice shelf (Fig. 7c). The newly decoupled portion will retain some of the characteristics of grounded ice until the zero basal shear stress at the ice/ocean interface imposes a near-zero surface slope, more consistent with an ice shelf (Thomas, 1979). Based on the evolution of surface features on Thwaites and Pine Island glaciers, we infer that this occurs on decadal timescales (Schmeltz and others, 2001; Jenkins and others, 2010). We refer to this stage of ice-plain evolution, where the ice is now freely floating but still possesses grounded-ice-like topography, as a 'relict ice plain'. This may be the floating margin to a remaining ice plain, such as for Möllereisstrom, or may extend landward to a regular GL (e.g. Fig. 1) at the ice-sheet coupling line, point $\mathrm{C}$, once the original ice plain is fully floating.

Observations of the three different stages of evolution of an ice plain and ephemeral grounding in the southern FRIS were facilitated by three factors: low bed slopes, a strong tidal signal and dynamic thinning. We have not considered the reasons for ice thinning in the southern portion of the FRIS GZ; however, it may be caused by dynamic thinning of the ice streams, increased basal melt rate due to changes in sub-ice-shelf oceanic circulation, or a long-term decrease in accumulation. Regardless of the cause, ice plains represent regions where fairly small perturbations in background environmental conditions can have a rapid and easily observed impact. Thus, having a benchmark for the precise flotation states of ice plains around Antarctica would be beneficial for monitoring of changes in ice-sheet margins on timescales of a few years.

\section{SUMMARY}

We have used ICESat repeat-track analysis to estimate the location of GZ features at 431 discrete locations around the perimeter of the FRIS. Through this mapping exercise, we have mapped three ice plains in the southern FRIS. These ice plains have previously been identified; however, the new observations allow us to redefine their areal extent and make some estimates of their basal slopes. We also use the new observations to develop a revised classification scheme for ice plains. We suggest that the progression through these different classifications represents the life cycle of an ice plain as the ice sheet thins near the GZ. Initially, the ice plain is fully (albeit lightly) grounded and not significantly perturbed by sea-level changes. As the ice thins it becomes ephemerally grounded, with some portion of the seaward ice plain lifting off the bedrock/till at high tide. Then, once sufficient thinning has occurred, the ice becomes a fully floating relict ice plain in which the ice retains topographic structure developed during its grounded phase (Fig. 7). We hypothesize that such topographic structure should relax over a timescale of decades; thus, a survey of relict ice plains around Antarctica may provide valuable information on GL retreats over several decades.

Coupled Earth-system numerical models that predict changes in the mass balance of ice sheets, including 
ice-flow and ocean models, are dependent on an accurate representation of ice shelves, and thus on the precise location of the GL. Our ICESat repeat-track analyses indicate that, in regions of low bed slope and with sufficient tidal amplitude, the GL can migrate by several kilometers during a half-tidal cycle ( $\sim 6$ hours). The presence of ice plains further complicates these models, as the GL is the boundary between the coupled ice-sheet and ice-shelf regimes, across which many factors change significantly over short distances. Ice plains add uncertainty to the absolute boundary between these regimes, as the precise nature of the flotation state in these regions can be ambiguous and may change on timescales that are short relative to typical time-steps used in ice-sheet modeling. Additionally, variables that generally change abruptly across the GL, such as basal shear stress, may change more gradually through the ice plain.

Migration of the GL implies that GZ mapping based on temporally limited datasets, such as the few images used to make a single differential SAR interferogram, may provide an inaccurate representation of the $\mathrm{GZ}$; this problem has been observed on the Amery Ice Shelf by Fricker and others (2009). The existence of floating relict ice plains also complicates GL detection through analyses of visible imagery such as MODIS. We conclude that GZ mapping is best performed through simultaneous analyses of multiple data types.

Finally, even though ice plains represent only a small fraction of the total Antarctic GZ ( $10 \%$ of the ICESatsampled GZ locations for the FRIS), their high sensitivity to small perturbations in ice-sheet mass-balance terms including basal melt rate, surface mass balance and dynamic changes in ice flow implies that they are valuable monitors of ice-sheet state. We propose that detailed mapping of all Antarctic ice plains, plus ongoing monitoring, provides the prospect of rapid detection of future changes in the icesheet margins.

\section{ACKNOWLEDGEMENTS}

We thank S. O'Neel for the development of the original graphical user interface associated with ICESat repeat-track analysis, and two anonymous reviewers for comments that greatly improved the manuscript. This work was supported by the NASA ICESat Project Science Office (see http:// icesat.gsfc.nasa.gov) and NASA grant NNX06AH39G to Earth \& Space Research (subcontract to Scripps Institution of Oceanography). We thank the US National Snow and Ice Data Center for distribution of the ICESat data (see http:// nsidc.org/data/icesat). This is Earth \& Space Research contribution No. 141.

\section{REFERENCES}

Alley, R.B., D.D. Blankenship, S.T. Rooney and C.R. Bentley. 1989. Sedimentation beneath ice shelves - the view from Ice Stream B. Mar. Geol., 85(2-4), 101-120.

Alley, R.B., S. Anandakrishnan, T.K. Dupont, B.R. Parizek and D. Pollard. 2007. Effect of sedimentation on ice-sheet grounding-line stability. Science, 315(5820), 1838-1841.

Anandakrishnan, S., G.A. Catania, R.B. Alley and H.J. Horgan. 2007. Discovery of till deposition at the grounding line of Whillans Ice Stream. Science, 315(5820), 1835-1838.

Benn, D.I. and D.J.A. Evans. 1998. Glaciers and glaciation. London, Arnold.
Bindschadler, R.A., P.L. Vornberger, M.A. King and L. Padman. 2003. Tidally driven stick-slip motion in the mouth of Whillans Ice Stream, Antarctica. Ann. Glaciol., 36, 263-272.

Bindschadler, R. and 17 others. 2011. Getting around Antarctica: new high-resolution mappings of the grounded and freelyfloating boundaries of the Antarctic ice sheet created for the International Polar Year. Cryos. Discuss., 5(1), 183-227.

Brunt, K.M., H.A. Fricker, L. Padman, T.A. Scambos and S. O'Neel. 2010. Mapping the grounding zone of Ross Ice Shelf, Antarctica, using ICESat laser altimetry. Ann. Glaciol., 51(55), 71-79.

Catania, G.A., C.L. Hulbe and H.B. Conway. 2010. Grounding-line basal melt rates determined using radar-derived internal stratigraphy. J. Glaciol., 56(197), 545-554.

Corr, H.F.J., C.S.M. Doake, A. Jenkins and D.G. Vaughan. 2001. Investigations of an 'ice plain' in the mouth of Pine Island Glacier, Antarctica. J. Glaciol., 47(156), 51-57.

Crabtree, R.D. and C.S.M. Doake. 1982. Pine Island Glacier and its drainage basin: results from radio-echo sounding. Ann. Glaciol., 3, 65-70.

Fricker, H.A. and L. Padman. 2002. Tides on Filchner-Ronne Ice Shelf from ERS radar altimetry. Geophys. Res. Lett., 29(12), 1622. (10.1029/2001GL014175.)

Fricker, H.A. and L. Padman. 2006. Ice shelf grounding zone structure from ICESat laser altimetry. Geophys. Res. Lett., 33(15), L15502. (10.1029/2006GL026907.)

Fricker, H.A., R. Coleman, L. Padman, T.A. Scambos, J. Bohlander and K.M. Brunt. 2009. Mapping the grounding zone of the Amery Ice Shelf, East Antarctica using InSAR, MODIS and ICESat. Antarct. Sci., 21(5), 515-532.

Gardner, A.S. and 8 others. 2011. Sharply increased mass loss from glaciers and ice caps in the Canadian Arctic Archipelago. Nature, 473(7347), 357-360.

Gray, L. and 6 others. 2002. RADARSAT interferometry for Antarctic grounding-zone mapping. Ann. Glaciol., 34, 269-276.

Heidrich, B., J. Sievers, H.W. Schenke and M. Thiel. 1992. Digitale topographische Datenbank Antarktis: die Küstenregionen vom westlichen Neuschwabenland bis zum Filchner-Ronne-Schelfeis interpretiert aus Satellitenbilddaten. Nachr. Kart. Verm., I(107), $127-140$

Jankowski, E.J. and D.J. Drewry. 1981. The structure of West Antarctica from geophysical studies. Nature, 291(5810), 17-21.

Jenkins, A. and 6 others. 2010. Observations beneath Pine Island Glacier in West Antarctica and implications for its retreat. Nature Geosci., 3(7), 468-472.

Joughin, I., B.E. Smith and D.M. Holland. 2010. Sensitivity of 21st century sea level to ocean-induced thinning of Pine Island Glacier, Antarctica. Geophys. Res. Lett., 37(20), L20502. (10.1029/2010GL044819.)

Lambrecht, A., H. Sandhager, D.G. Vaughan and C. Mayer. 2007. New ice thickness maps of Filchner-Ronne Ice Shelf, Antarctica, with specific focus on grounding lines and marine ice. Antarct. Sci., 19(4), 521-532.

Padman, L., H.A. Fricker, R. Coleman, S. Howard and L. Erofeeva. 2002. A new tide model for the Antarctic ice shelves and seas. Ann. Glaciol., 34, 247-254.

Rignot, E.J. 1998. Fast recession of a West Antarctic glacier. Science, 281(5376), 549-551.

Scambos, T., J. Bohlander, B. Raup and T. Haran. 2004. Glaciological characteristics of Institute Ice Stream using remote sensing. Antarct. Sci., 16(2), 205-213.

Scambos, T.A., T.M. Haran, M.A. Fahnestock, T.H. Painter and J. Bohlander. 2007. MODIS-based Mosaic of Antarctica (MOA) data sets: continent-wide surface morphology and snow grain size. Remote Sens. Environ., 111(2-3), 242-257.

Schmeltz, M., E. Rignot and D.R. MacAyeal. 2001. Ephemeral grounding as a signal of ice-shelf change. J. Glaciol., 47(156), 71-77.

Schoof, C. 2007. Ice sheet grounding line dynamics: steady states, stability, and hysteresis. J. Geophys. Res., 112(F3), F03S28. (10.1029/2006JF000664.) 
Schutz, B.E., H.J. Zwally, C.A. Shuman, D. Hancock and J.P. DiMarzio. 2005. Overview of the ICESat Mission. Geophys. Res. Lett., 32(21), L21S01. (10.1029/2005GL024009.)

Shuman, C.A. and 6 others. 2006. ICESat Antarctic elevation data: preliminary precision and accuracy assessment. Geophys. Res. Lett., 33(7), L07501. (10.1029/2005GL025227.)

Smith, A.M. 1991. The use of tiltmeters to study the dynamics of Antarctic ice-shelf grounding lines. J. Glaciol., 37(125), 51-58.

Smith, B.E., H.A. Fricker, I.R. Joughin and S. Tulaczyk. 2009. An inventory of active subglacial lakes in Antarctica detected by ICESat (2003-2008). J. Glaciol., 55(192), 573-595.

Thomas, R.H. 1979. The dynamics of marine ice sheets. J. Glaciol., 24(90), 167-177.
Vaughan, D.G. 1994. Investigating tidal flexure on an ice shelf using kinematic GPS. Ann. Glaciol., 20, 372-376.

Winberry, J.P., S. Anandakrishnan, R.B. Alley, R.A. Bindschadler and M.A. King. 2009. Basal mechanics of ice streams: insights from the stick-slip motion of Whillans Ice Stream, West Antarctica. J. Geophys. Res., 114(F1), F01016. (10.1029/ 2008JF001035.)

Zwally, H.J. and 7 others. 2005. Mass changes of the Greenland and Antarctic ice sheets and shelves and contributions to sealevel rise: 1992-2002. J. Glaciol., 51(175), 509-527.

Zwally, H.J. and 11 others. 2011. Greenland ice sheet mass balance: distribution of increased mass loss with climate warming; 2003-07 versus 1992-2002. J. Glaciol., 57(201), 88-102.

MS received 8 February 2011 and accepted in revised form 25 July 2011 